\title{
Evaluation of remediation in heavy metal tolerance and removal by Comamonas acidovorans MTCC 3364
}

\author{
Darshan M. Rudakiya* and Kirti S. Pawar \\ Ashok \& Rita Patel Institute of Integrated Study and Research in Biotechnology and Allied Sciences, New \\ Vallabh Vidyanagar, Anand, Gujarat, 388121.
}

\begin{abstract}
Comamonas acidovorans has vital role in degradation of natural as well as complex organic compounds. Comamonas acidovorans MTCC 3364 is mainly used for bioconversion of different steroids but now it is a novel approach on bioremediation. In heavy metals hexavalent chromium, mercury and lead is very toxic and carcinogenic for human health. Organism can tolerate heavy metals like hexavalent chromium, mercury, lead and aluminium with high efficiency. Removal of hexavalent chromium is major problem to textile as well as different industries. Comamonas acidovorans MTCC 3364 removed 99\% of the hexavalent chromium from the medium and it can tolerate up to $600 \mathrm{ppm}$ of chromium and 200 ppm of mercury in solidified medium. This organism shows high tolerance against salt i.e. it can tolerate up to $10 \%$ of salt. Chromium removal was also observed by using biosorption studies and MIC method. This bacteria increases $p H$ during removal of chromium and makes chromium oxide which is trivalent chromium; it is a non-toxic compound. High salt tolerance, heavy metal tolerance and removal of hexavalent chromium make applicability in the treatment of waste water technology and treatment of industrial effluent which contain high amount of salt and heavy metals.

Keywords: antibiotic resistance, Comamonas acidovorans MTCC 3364, heavy metal tolerance, hexavalent chromium removal, salt tolerance
\end{abstract}

\section{Introduction}

Heavy metals such as mercury, chromium, lead and arsenic are toxic metals that have no known vital or beneficial effect on organisms. Heavy metal toxicity can result in damaged or reduced mental and central nervous function, lower energy levels, and damage to blood composition, lungs, kidneys, liver, and other vital organs. Long-term exposure may result in slowly progressing physical, muscular, and neurological degenerative processes. Extensive application of chromium in industries particularly metal finishing industries, petroleum refining, leather tanning, iron and steel industries, inorganic chemical production, textile manufacturing and pulp production industries[1-2] leads to the formation of chromium-contaminated soil and ground water which pose a serious threat to living organism particularly to human health [3-4]. Chromium is a potent pollutant which is mutagenic, carcinogenic and teratogenic in humans, animals and plans [5-7].

Mercury-contaminated soils and sediments are commonly remediated by soil excavation, relocation, and burial; soil washing with halogenated substances; heating soil to high temperature. In general, treatment of effluents includes physiochemical methods such as filtration, specific coagulation, use of activated carbon and chemical flocculation [8]. However, a majority of these technologies are costly to implement and cause further disturbance to the already damaged environment [9]. Biological treatment methods using different bacteria, fungi and plants have been widely studies. Biological reduction of hexavalent chromium to and its precipitation into immobile trivalent by chromium resistant microbes is considered to be an effective method for detoxification of chromium-contaminated environments and have a potential use in bioremediation. Reduction of chromium has been demonstrated in various bacterial species including Escherichia coli [10], Pseudomonas putida [11], Desulfovibrio sp. [12], Bacillus sp.[13] and Arthrobacter sp. [14] and actinomycetes [15]. The response of microorganisms towards toxic heavy metals is of importance in view of their interest in the reclamation of polluted sites. Several studies have indicated a co-relation between antibiotic resistance and heavy metal resistance [16-17].

Comamonas acidovorans is belonging from Comamonadaceae family of the $\beta$-proteobacteria. It has vital role in degradation of natural as well as complex organic compounds like 4-nitrobenzoate and cocaine [1819]. Comamonas acidovorans MTCC 3364 has been routinely reported for bioconversion of different steroids like progesterone, testosterone and cholesterol [20-21]. The main purpose of study was to investigate efficacy of heavy metal tolerance and effective removal of hexavalent chromium by Comamonas acidovorans MTCC 3364. Efficient hexavalent chromium removal was also observed by using different parameters like time of addition, split dose, concentration of chromium and $\mathrm{pH}$ of the medium was also observed. Conversion of hexavalent to trivalent chromium was also observed and biosorption mechanism was studied by using free live and dead cells of an organism. Co-relation between chromium resistant bacteria and $\beta$-lactam antibiotics was also studied. 


\section{Materials And Methods}

\subsection{Chemical and reagents}

Nutrient broth, nutrient agar, ampicillin $(10 \mathrm{mcg})$ and penicillin $\mathrm{G}$ (10 units) discs were purchased from Sigma Pvt. Ltd. Diphenyl carbazide, sodium chloride, potassium dichromate, potassium chromate, mercury chloride, silver nitrate, lead nitrate, aluminium chloride and stannous chloride was purchased from Merck Specialities Pvt. Ltd. Acetone and concentrated sulphuric acid were purchased from standard Indian suppliers. All chemicals are highly pure and analytical graded.

\subsection{Micro-organisms and culture conditions}

Comamonas acidovorans MTCC 3364 was purchased from Microbial Type Culture Collections, Institute of Microbial Technology, Chandigarh, India. The pure culture was maintained on nutrient agar slants and stored at $4^{\circ} \mathrm{C}$. The organism was sub-cultured every month. Heavy metal tolerance studies and chromium removal studies were performed using nutrient broth medium $(13 \mathrm{~g} / \mathrm{L})$.

\subsection{Maximum Tolerance Concentration studies of heavy metals}

Different heavy metals were used to study maximum efficacy of heavy metal tolerance of an organism. All metals had been grown along with nutrient medium by varying different concentration of heavy metals like chromium, mercury, lead, silver, stannous and aluminium. $20 \mathrm{ml}$ of nutrient broth $(13 \mathrm{gm} / \mathrm{lit})$ were autoclaved, cooled and then inoculated with $100 \mu \mathrm{l}$ of previous grown culture. Flasks were incubated on rotary shaker at $37^{\circ} \mathrm{C}$ for overnight. Next day, 100 to $500 \mathrm{ppm}$ of sterilized heavy metals was added and observed after 24 hours.

\subsection{Chromium removal studies}

$20 \mathrm{ml}$ of nutrient broth $(13 \mathrm{gm} / \mathrm{lit})$ were autoclaved, cooled and then inoculated with $100 \mu \mathrm{l}$ of previous grown culture. Flasks were incubated on rotary shaker at $37^{\circ} \mathrm{C}$ for overnight. Next day, 100 to $500 \mathrm{ppm}$ of sterilized chromium $\left(\mathrm{K}_{2} \mathrm{Cr}_{2} \mathrm{O}_{7}\right.$ and $\left.\mathrm{K}_{2} \mathrm{CrO}_{4}\right)$ was added to the flasks and incubated for 72 hours at $37^{\circ} \mathrm{C}$ in shaking condition. Samples were withdrawn and OD was determined for chromium at interval of 24 hours using diphenyl carbazide method.

\subsection{Effect of time of addition of Chromium with split dose}

Following variants for chromium addition were selected: [1] Flask containing $20 \mathrm{ml}$ of nutrient broth and $100 \mathrm{ppm}$ of chromium were autoclaved, cooled and then inoculated with $100 \mu \mathrm{l}$ of Comamonas acidovorans MTCC 3364 culture. [2] Flask containing $20 \mathrm{ml}$ of overnight grown culture and then $100 \mathrm{ppm}$ of chromium was added. Both flasks were incubated for 48 hours at $37^{\circ} \mathrm{C}$ at shaking condition. Samples were withdrawn and OD was determined for chromium at interval of 24 hours by using DPC method. $200 \mathrm{ppm}$ of Chromium was again added after 48 hours to observe split dose studies and OD was again determined at interval of 24 hours by using DPC method.

\section{$2.6 \mathrm{pH}$ observation studies}

$100 \mathrm{ml}$ of nutrient broth was taken and $\mathrm{pH}$ observed, autoclaved it and inoculated $100 \mathrm{ml}$ of culture of organism. $5 \mathrm{ml}$ of sample was withdrawn aseptically, $\mathrm{pH}$ observed and flasks were again incubated at $37^{\circ} \mathrm{C}$ at shaking condition. Next day, $100 \mathrm{ppm}$ of chromium $\left(\mathrm{K}_{2} \mathrm{Cr}_{2} \mathrm{O}_{7} \& \mathrm{~K}_{2} \mathrm{CrO}_{4}\right)$ added, sample was collected again and $\mathrm{pH}$ observed for 96 hours.

\subsection{Chromium removal studies using free cells}

$20 \mathrm{ml}$ of Culture was transferred into centrifuge tube aseptically and centrifuge at $10,000 \mathrm{rpm}$ for 10 minutes. Cells harvested and suspended in phosphate buffer (pH 6.85). 100 ppm, 200 ppm and 300 ppm of chromium $\left(\mathrm{K}_{2} \mathrm{Cr}_{2} \mathrm{O}_{7}\right.$ and $\left.\mathrm{K}_{2} \mathrm{CrO}_{4}\right)$ was added and incubated for 24 hours at $37^{\circ} \mathrm{C}$ at shaking condition. Chromium estimated at interval of 2 hours and calculated \% chromium removal. Biosorption was also studied using Energy Dispersive Analysis of X-Ray (EDAX).

\subsection{Chromium removal studies using dead cells}

$20 \mathrm{ml}$ of culture was transferred it into centrifuge tube aseptically. Centrifuge at 10,000 rpm for 10 minutes. Cells were harvested, resuspended in phosphate buffer $(\mathrm{pH}$ 6.85) and autoclaved for 15 minute at $121^{\circ} \mathrm{C} .100 \mathrm{ppm}$ of chromium was added and incubated for 24 hours at $37^{\circ} \mathrm{C}$ at shaking condition. Chromium estimated at interval of 2 hours and calculated \% chromium removal.

\subsection{Chromium, mercury and salt tolerance studies on solidified medium}

Plates containing nutrient agar with 100-500 ppm of Chromium $\left(\mathrm{K}_{2} \mathrm{Cr}_{2} \mathrm{O}_{7} \& \mathrm{~K}_{2} \mathrm{CrO}_{4}\right)$ and $50-250 \mathrm{ppm}$ of mercury $\left(\mathrm{HgCl}_{2}\right)$ were prepared respectively and plates containing nutrient agar with $0.5 \%$ to $20 \%$ of 
sodium were also prepared. $100 \mu \mathrm{l}$ of organism was poured in each plate, solidified it and incubated for 24 hours at $37^{\circ} \mathrm{C}$. Next day results were observed.

\subsection{Effect of $\beta$-lactam antibiotics on Chromium resistant Comamonas acidovorans MTCC 3364}

Nutrient broth containing $200 \mathrm{ppm}$ of chromium along with $100 \mu \mathrm{l}$ of culture was prepared and incubated for 24 hour at $37^{\circ} \mathrm{C}, 120 \mathrm{rpm}$ rotary shaker. Next day Nutrient agar plates were prepared and chromium resistant Comamonas acidovorans MTCC 3364 culture was spread on nutrient agar plates. Antibiotic discs (ampicillin and penicillin G) were kept on the centre of the plates. All the plates were incubated overnight at $37^{\circ} \mathrm{C}$. Negative control (without chromium) plates were also prepared for comparative study.

\subsection{Maximum Tolerance Concentration studies of heavy metals}

\section{Result And Discussions}

Comamonas acidovorans MTCC 3364 could efficiently tolerate up to $600 \mathrm{ppm}$ of hexavalent chromium, $200 \mathrm{ppm}$ of mercury, $500 \mathrm{ppm}$ of lead, $400 \mathrm{ppm}$ of silver, $350 \mathrm{ppm}$ of stannous and $500 \mathrm{ppm}$ of aluminium. This data showed that Comamonas acidovorans MTCC 3364 has high tolerance efficacy in terms of heavy metals specially it tolerated hexavalent chromium, lead and aluminium with highest efficacy. Highest tolerance might be involved in the organism either presence of cross-resistance with heavy metals or presence of plasmid [17].

\subsection{Chromium Removal studies}

The results of chromium removal by Comamonas acidovorans MTCC 3364 have been. Organism removed $99.40 \%$ of 100 ppm K ${ }_{2} \mathrm{CrO}_{4}$ within 48 hours and $98.70 \%$ of $100 \mathrm{ppm} \mathrm{K}_{2} \mathrm{Cr}_{2} \mathrm{O}_{7}$. Cells were also removed $98 \%$ of $200 \mathrm{ppm}$ of chromium efficiently. It removed chromium up to $400 \mathrm{ppm}$. Woo Chul Bae showed that E.coli removed chromium 40 ppm within 20 hours whereas Comamonas removed 100 ppm efficiently within 48 hours suggesting the suitability of the organism for treatment of Industrial effluent containing large amount of chromium at $37^{\circ} \mathrm{C}$ and $\mathrm{pH} 7.0 \pm 0.02[2]$.

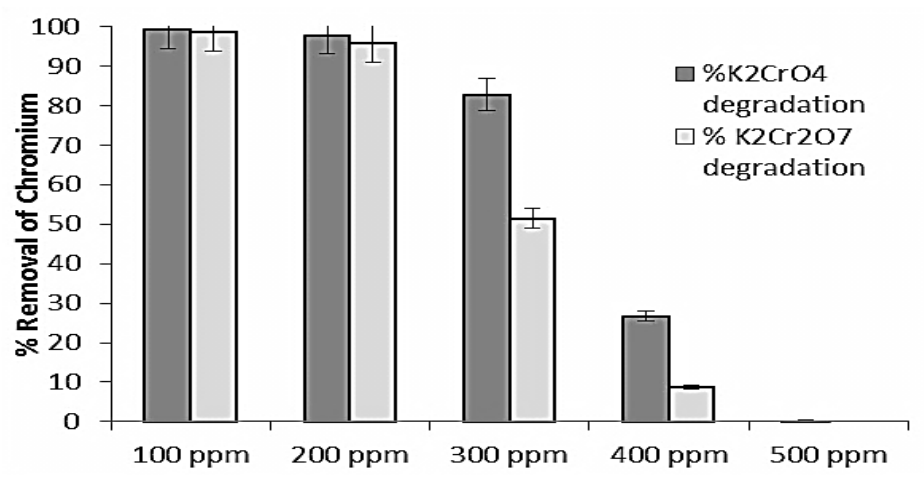

Fig. 1 Chromium Removal by Comamonas acidovorans MTCC 3364

\subsection{Effect of time of addition of Chromium with split dose}

To study the effect of chromium on growth and decolorization, chromium was added to the reaction medium either during inoculation or after overnight growth. Removal of chromium was followed after $24 \mathrm{hrs}$. The results have been shown in Fig. 2 and 3 which clearly depict that organisms removed efficiently chromium when chromium was added before growth. It showed efficiently removal of chromium even after split dose. Medium showed green color after 72-96 hours after inoculation of organisms. This indicated that chromium (+6) was converted into chromium oxide; which has significant importance in textile, paper and other industries [22].

\section{$3.4 \mathrm{pH}$ observation studies}

The $\mathrm{pH}$ change in the medium was suspected to be the cause of change in color of the medium and was confirmed by measuring the $\mathrm{pH}$ of colored medium which was found to be between 8 and 9 . It is a major application from the point of view of bioremediation and industrial aspects in that hexavalent chromium converted into trivalent chromium only if alkaline condition is possible so removal of chromium was beneficial. K.Poornima et al also reported $\mathrm{pH}$ studies during removal of chromium [22] [25]. 


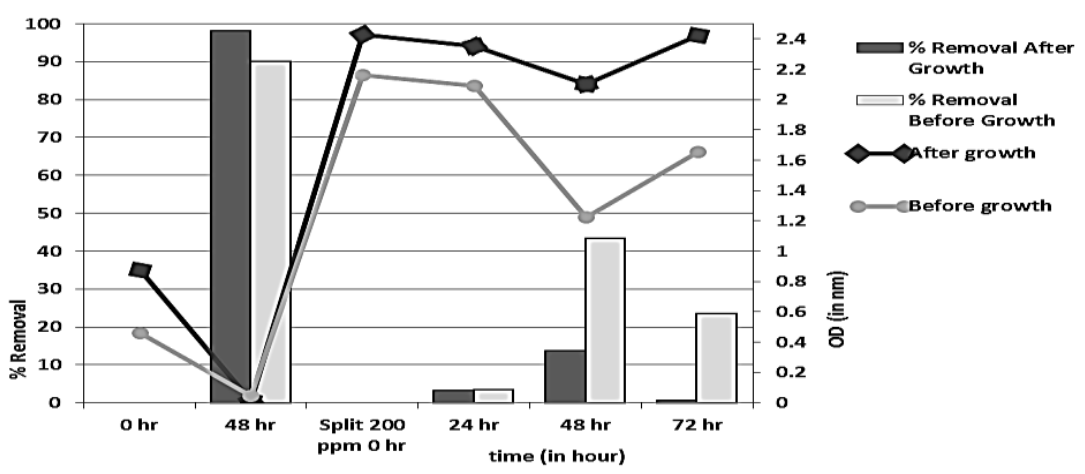

Fig. 2 Effect of time of addition of $\mathrm{K}_{2} \mathrm{Cr}_{2} \mathrm{O}_{7}$ with split dose

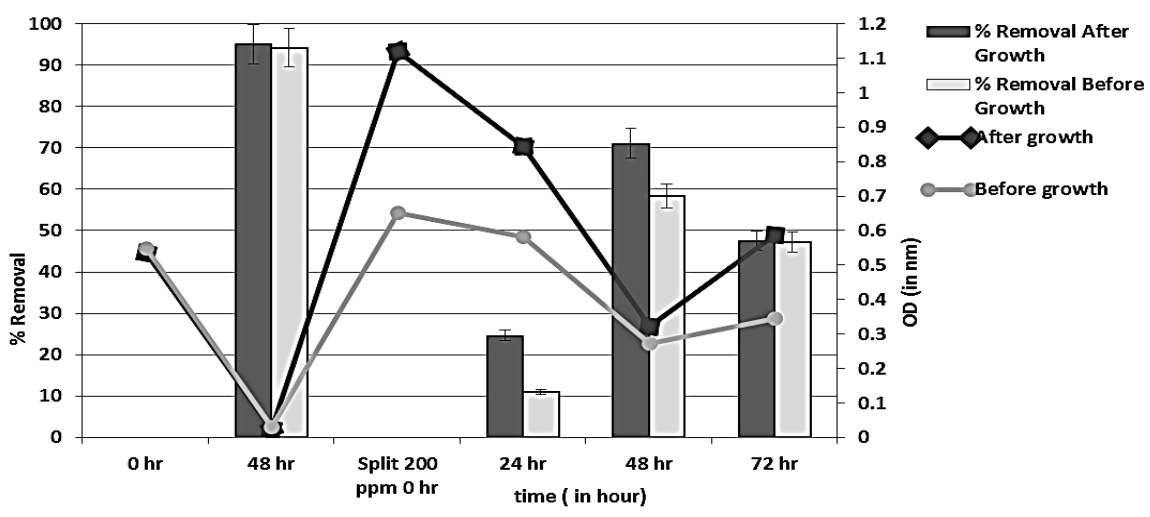

Fig. 3: Effect of chromium time of addition of $\mathrm{K}_{2} \mathrm{CrO}_{4}$ with split dose

Table 1 pH observation studies during removal of chromium

\begin{tabular}{|c|c|c|c|}
\hline Condition & $\begin{array}{c}\text { Nutrient broth } \\
\text { (Control) }\end{array}$ & $\begin{array}{c}\text { Nutrient broth with } \\
\mathbf{K}_{\mathbf{2}} \mathbf{C r}_{\mathbf{2}} \mathbf{O}_{\mathbf{7}}\end{array}$ & $\begin{array}{c}\text { Nutrient broth with } \\
\mathbf{K}_{\mathbf{2}} \mathbf{C r O}_{\mathbf{4}}\end{array}$ \\
\hline Before autoclaving & 6.85 & 7.03 & 7.15 \\
\hline $\begin{array}{c}\text { After autoclaving and } \\
\text { inoculation }\end{array}$ & 6.89 & 7.17 & 7.35 \\
\hline $\mathbf{2 4}$ hour & 6.92 & 7.98 & 8.24 \\
\hline $\mathbf{4 8}$ hour & 6.95 & 8.27 & 8.52 \\
\hline $\mathbf{7 2}$ hour & 6.98 & 8.86 & 8.99 \\
\hline $\mathbf{9 6}$ hour & 7.00 & 9.08 & 9.32 \\
\hline
\end{tabular}

\subsection{Chromium removal studies using free cells}

In order to test the reusability and importance of metabolic activity of cells for chromium removal, the cells of the organism were harvested from overnight grown culture and incubated with the chromium in buffered medium. The results of free cells for chromium removal are depicted in Fig. 4 (A). Free cells showed almost half of the chromium removal by biosorption. Chromium was removed almost $50-56 \%$ by biosorption studies so it is indicative that metabolic function of cells in not mandatory for chromium removal by this organism. P. Saranraj et al also suggested that biosorption also occurred by live and dead cells of Enterococcus casseliflavus [23].
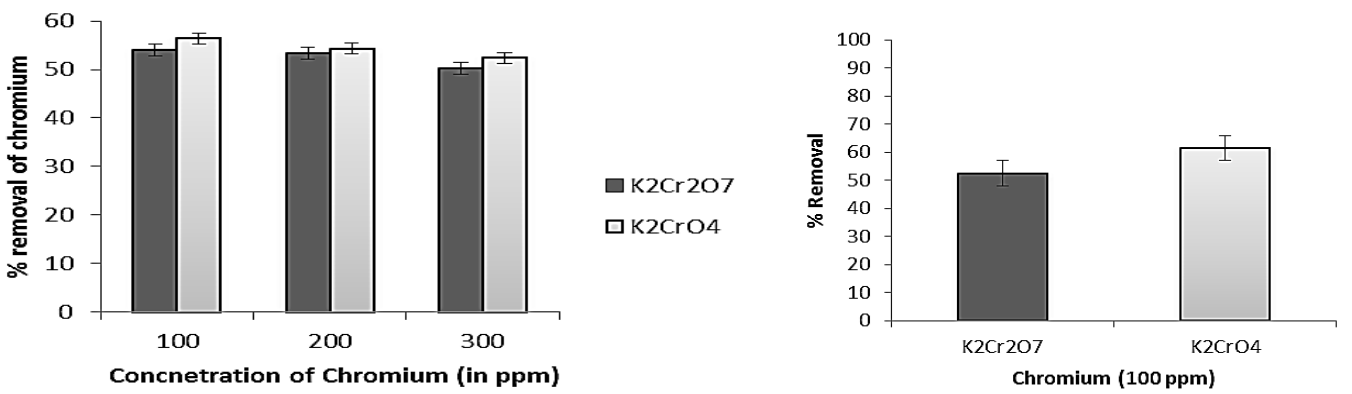

Fig. 4 Chromium removal using free (A) live cells (100-300 ppm) (B) dead cells (100 ppm) (Biosorption studies) 


\subsection{Chromium removal studies using dead cells}

Chromium removal studies also cross checked with the biosorption studies. Dead cells also showed 52$61 \%$ of removal of chromium which highlighted in Fig. 4 (B) that presented the role of biosorption in contributing towards removal of metals by Comamonas acidovorans MTCC 3364 [23]. EDAX analysis of free cells suspended in buffer containing 100 ppm of chromium, which was detected under Energy Dispersive X-ray analyser, showed a peak of chromium in EDAX graph as shown in Fig. 5 [25].

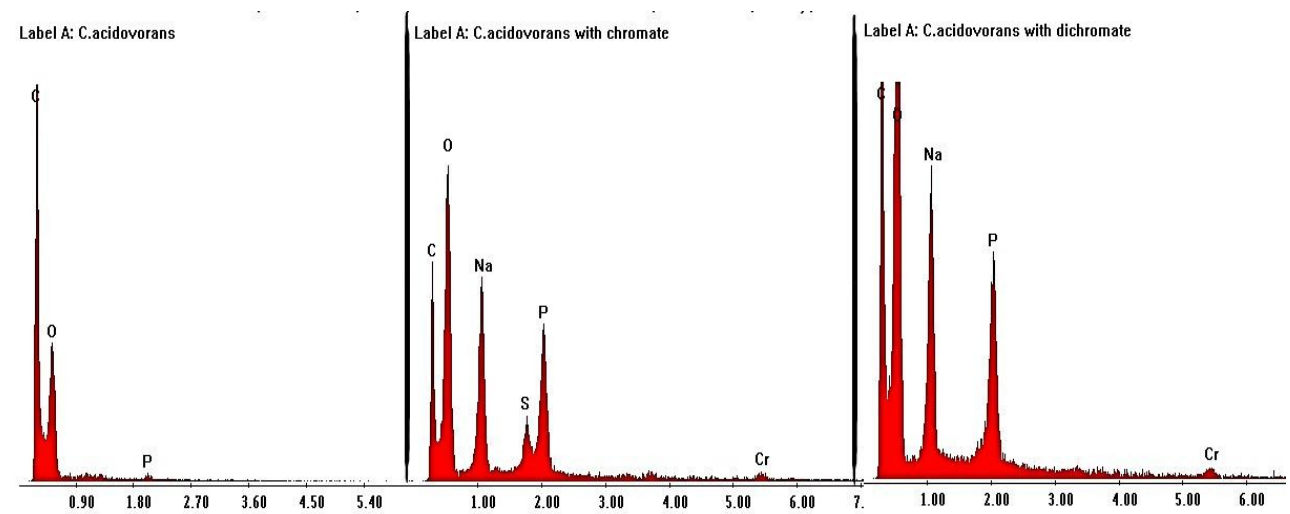

Fig. 5 EDAX spectrums of (A) culture of Comamonas acidovorans MTCC 3364 (control), (B) cells incubated with potassium chromate and $(C)$ cells incubated with potassium dichromate

\subsection{Chromium studies on solidified medium}

Growth was observed on solidified medium showed that organism can tolerate up to $600 \mathrm{ppm}$ of chromium in solidified medium but it showed some spotted colony on $700 \mathrm{ppm}$ containing chromium plates and up to 200 ppm of mercury. Comamonas acidovorans MTCC 3364could also tolerate 10\% of salt in the medium. This data depicts that some detergent or textile industries contained high amount of salt or alkalinity in their effluents so this organism could also survive up to $10 \%$ of salt concentration. It is significant in waste water technology and textile industries that contained high concentration of heavy metals and high amount of salts so it can tolerate high concentration of salt along with chromium and simultaneously mercury.

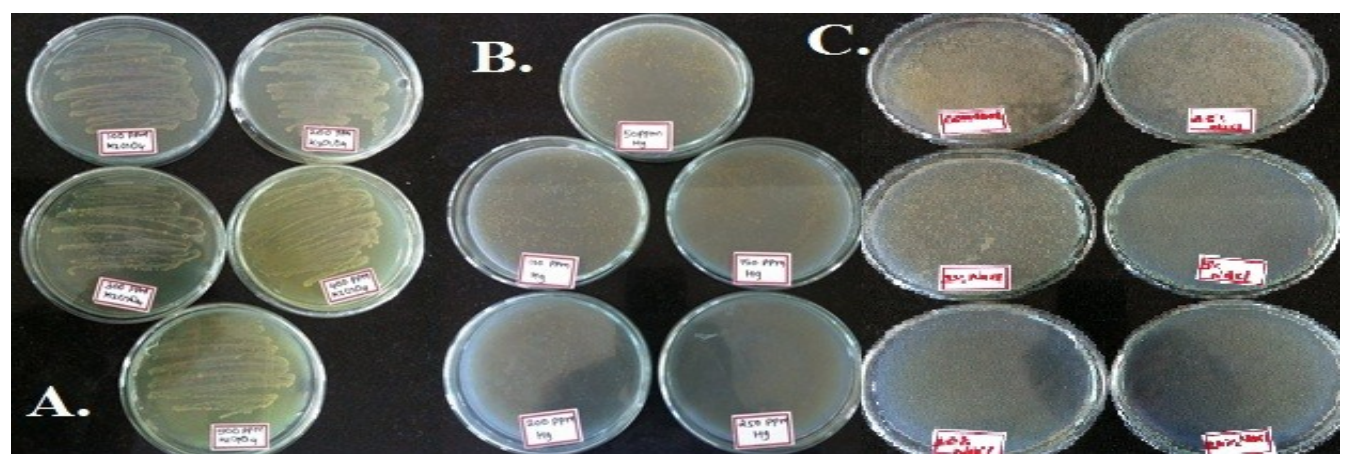

Fig. 6 Growth of Comamonas acidovorans MTCC 3364 on solidified medium contained (A) chromium up to $500 \mathrm{ppm}$ (B) mercury up to $250 \mathrm{ppm}$ (C) salt concentration up to $20 \%$.

\subsection{Effect of various antibiotics on Chromium resistant Comamonas acidovorans MTCC 3364}

Relation between antibiotics and heavy metals is significant prospectus for industrial purpose. Comamonas acidovorans MTCC 3364 showed tolerance for the chromium at higher concentration. It directly affected on antibiotic resistance on normal Comamonas acidovorans MTCC 3364 cells. Chromium resistant cells showed less sensitivity against antibiotics. It is showed in Fig. 7. 


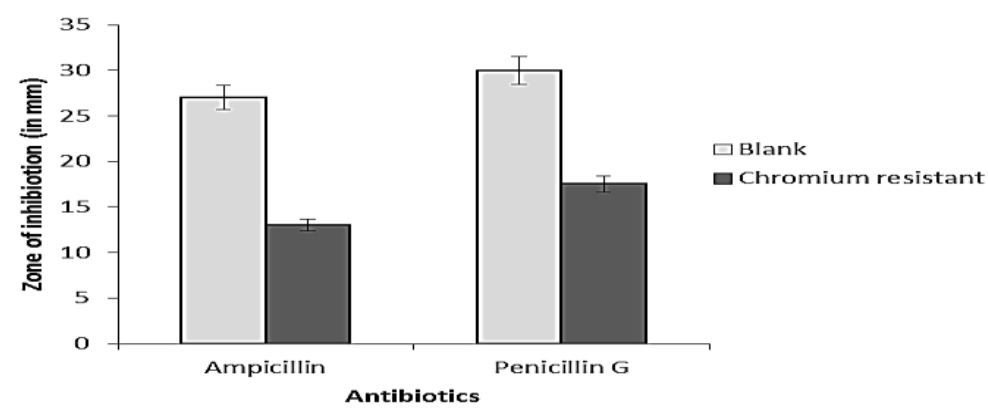

Fig. 7 Comparison of $\beta$-lactam antibiotics between chromium resistant bacteria and control (without any
metal)

\section{Conclusion}

Comamonas acidovorans MTCC 3364 could tolerate heavy metals with high efficiency. The strain could be efficiently applied for removal of high concentration of chromium from the industrial effluents. Biosorption and chemical reduction have been indicated to play role in chromium removal by the strain. $\mathrm{pH}$ observation studies and EDAX analysis revealed that hexavalent chromium is converted in to less toxic and useful compound chromium oxide which is trivalent. Organism showed high resistant activity against $\beta$-lactam antibiotics when chromium is present in medium. Thus, Comamonas acidovorans MTCC significant in waste water technology and textile industries that contained high concentration of heavy metals and high amount of salts.

\section{Acknowledgement}

The authors acknowledge Charutar Vidya Mandal, Vallabh Vidyanagar, Anand for providing the infrastructure, laboratory, chemicals, computational and other necessary facilities for the successful completion of this work. Authors also thank to MTCC for providing the cultures used in the study and SICART, Vallabh Vidyanagar for extending analytical facilities for this study.

\section{References}

[1]. Patterson, J.W. 1985. Industrial wastewater treatment technology. p53-393 Butterworth Pubilisher, Stoneham, MA

[2]. Woo Chul Bae, Tae Gu Kang, In Kyong Kang, You Jung Won and Byeong Chul Jeong 2000. Reduction of Hexavalent Chromium by Escherichia coli ATCC 33456 in Batch and Continuous Cultures. The Journal of Microbiology; 38(1), 36-39.

[3]. Sankar Narayan Sinha, Mrinal Biswas, Dipak Paul, Saidur Rahaman 2011. Biodegradation potential of bacterial isolates from tannery effluent with special reference to hexavalent chromium. Biotechnol. Bioinf. Bioeng., 1(3), 381-386.

[4]. Petrilli FL, Flora SD. Appl. Environ. Microbiol. 1977, 33, 805-809.

[5]. Gruber JE, Jennette KW. Biochem. Biophys. Res. Commun. 1978, 82, 700-706.

[6]. Gale TF 1978. Environmental Research, 16, 101-109.

[7]. Flora SD, Bagnasco M, Serra D, Zanacchi P 1990. Mutatant Research, 238, 99-172.

[8]. Olukanni, O.D., Osuntoki, A.A and Gbenle, G.O. 2006. Textile effluent biodegradation potentials of textile effluent-adapted and non-adapted bacteria. African Journal of Biotechnology, 5 (20), 1980-1984.

[9]. US Environmental Protection Agency, Introduction to Phytoremediation, EPA/600/R-99/107 (2000)

[10]. Shen, H. and Y.T. Wang, 1993. Characterization of enzymatic reduction of hexavalent chromium by Escherichia coli ATCC 33456. Applied Environ. Microbiol., 59, 3771-3777. PMID: 8285683

[11]. Ishibashi, Y., C. Cervantes and S. Silver, 1990. Chromium reduction in Pseudomonas putida. Applied Environ. Microbiol., 56, 2268-2270. PMID: 2389940

[12]. Mabbett, A.N. and L.E. Macaskie, 2001. A novel isolates of Desulfovibrio Sp. With the enhanced ability to reduce Cr (VI). Biotechnol. Lett., 23, 683-687. DOI: 10.1023/A:1010352417399.

[13]. Liu, Y.G., W.H. Xu, G.M. Zeng, X. Li and H. Gao, 2006. Cr(VI) reduction by Bacillus sp. isolated from chromium landfill. Process Biochem., 41, 1981-1986. DOI: 10.1016/j.procbio.2006.04.020

[14]. Asatiani, N.V., M.K. Abuladze, T.M. Kartvelishvili, N.G. Bakradze and N.A. Sapojnikova et al., 2004. Effect of chromium (VI) action on Arthrobacter oxydans. Curr. Microbiol., 49, 321-326. DOI: 10.1007/s00284-004-4351-2

[15]. Polti, M.A., R.O. García, M.J. Amoroso and C.M. Abate, 2009. Bioremediation of chromium (VI) contaminated soil by Streptomyces sp. MC1. J. Basic Microb., 49, 285-292. DOI: 10.1002/jobm. 200800239.

[16]. Bahig, A.E., E.A. Aly, A.A. Khaled and K.A. Amel, 2008. Isolation, characterization and application of bacterial population from agricultural soil at Sohag Province, Egypt. Malaysian J. Microbiol., 4, 42-50.

[17]. Craig Baker-Austin, Meredith S. Wright, Ramunas Stepanauskas and J.V. McArthur 2006. Co-selection of antibiotic and metal resistance. Trends in Microbiology 14 No.4. 176-182.

[18]. Peter, G., Bont, J., 1992. Degradation of 4-nitrobenzoate via 4-hydroxylaminobenzoate and 3,4-dihydroxybenzoate in Comamonas acidovorans NBA-10. Achieves in Microbiology 158, 381-386.

[19]. Lister, D.L., Sproule, R.F., Britt, A.J., Lowe, C.R., Bruce, N.C., 1996. Degradation of Cocaine by a Mixed Culture of Pseudomonas fluorescens MBER and Comamonas acidovorans MBLF. Applied and Environmental Microbiology 62, 94-99.

[20]. Pawar, K., Lad, N., Pawar, S.P., 2011. Simultaneous Spectroscopic estimation of 11- $\beta$, 17- $\alpha$, 21-trihydroxy-4-pregnene-3, 20-dione, 21-o-succinate and its 1(2)-Dehydrogenated Product during Bioconversion by Comamonas acidovorans MTCC 3364.Recent Research in Science and Technology 3, 01-04.

[21]. Rudakiya Darshan and Pawar Kirti, 2013. Bioconversion of progesterone using aqueous two phase system by Comamonas acidovorans MTCC 3364. International Journal of Biotechnology 111, 211-214. 
[22]. K.Poornima, L.karthik, S.P.Swadhini, S.Mythili and A.Sathiavelu 2010. Degradation of Chromium by using a novel Strains of Pseudomonas Species. Journal of Microbial \& Biochemical Technology; 2(4), 095-099.

[23]. Booth C. 1971. Methods in Microbiology. 1st Edition, Academic Press, London, ISBN-10: 0125215045, $795-799$.

[24]. Carol A. Clausen 2000. Isolating metal-tolerant bacteria capable of removing copper, chromium, and arsenic from treated wood. Waste Management Resources; 18, 264-268.

[25]. Donghee Parka, Yeoung-Sang Yunb and Ji Hye Joa 2005. Mechanism of hexavalent chromium removal by dead fungal biomass of Aspergillus niger. Water Research; 39(4), 533-540.

[26]. Hai Shen and Yi-Tin Wang 1995. Chromium Reduction and Phenol Degradation in a Co-culture of Escherichia coli ATCC 33456 and Pseudomonas putida DMP1. Applied and Environmental Microbiology; volume 61(7), pages 2754-2758.

[27]. Ozturk S, Kaya T, Aslim B and Tan S (2012). Removal and reduction of chromium by Pseudomonas spp. and their correlation to rhamnolipid production. Journal of Hazard Mater; 15, 231-232.

[28]. R. Gopalan, H. Veeramani 1994. Studies on microbial chromate reduction by Pseudomonas sp. in aerobic continuous suspended growth cultures. Journal of Biotechnology and Bioengineering; 43, 471-476.

[29]. Srivastava J, Chandra H, Tripathi K, Naraian R and Sahu RK 2008. Removal of chromium (VI) through biosorption by the Pseudomonas spp. isolated from tannery effluent. Journal of Basic Microbiology; 48(2), 135-139. 